\title{
Aseguramiento en los Regímenes Contributivo y Subsidiado, e Impacto en los Prestadores de Servicios $^{1}$
}

\author{
Luis M. Prada B. \\ Administrador de Empresa. M. Sc. Docencia. Universidad Nacional de Colombia. Facultad \\ de Ciencias Económicas. Centro de Investigaciones para el Desarrollo-CID. \\ E-mail: lmpradab@unal.edu.co
}

\section{RESUMEN}

Con el fin de establecer el margen que logran las Entidades Promotoras de Salud- EPS en su labor de administración del seguro de salud, se utilizó información de los estados de resultados y balances generales para 1997, 1998 y 1999 entregados a la Superintendencia Nacional de SaludSNS por 18 EPS privadas y Cajas de Compensación Familiar-CCF. Para disminuir el efecto de los casos extremos, el análisis se hizo sobre el comportamiento promedio de cada partida de resultados o de balance, para lo cual el valor de cada EPS se ponderó por el número de afiliados. Así es posible establecer el comportamiento esperado de los costos y gastos de una entidad cuyo negocio central sea el aseguramiento en salud. Las EPS privadas tienen como fuente principal de ingresos operacionales la Unidad de Pago por Capitación-UPC del régimen contributivo. La participación del régimen subsidiado y de las otras fuentes de ingresos es cada año menor. Por el contrario, las EPS públicas denotan una participación cada vez menor de los ingresos por UPC (contributiva y subsidiada) y una creciente dependencia de los otros ingresos, lo cual puede tomarse como síntoma de una gestión comercial débilDe acuerdo con los estados de resultados suministrados por la SNS, incluido el ISS, las EPS (públicas, privadas y CCF) lograron un total de ingresos operacionales de \$ 4,18 billones en 1999, lo cual significó un incremento de $21,7 \%$ con respecto a 1998. Los ingresos del Instituto de Seguros Sociales-ISS fueron de \$1,93 billones en

\footnotetext{
${ }^{1}$ Los contenidos del artículo, aunque sólo comprometen al autor, se basan en los resultados y conclusiones que sobre el tema de la identificación y selección de beneficiarios ha obtenido el Proyecto Evaluación de los procesos del Régimen Subsidiado en Salud, realizado por el Centro de Investigaciones para el Desarrollo (CID) de la Universidad Nacional de Colombia, mediante contrato con el Ministerio de Salud de Colombia (Programa de Apoyo a la Reforma de Salud) y con financiación del Banco Interamericano de Desarrollo (BID). Los informes de investigación sobre éste y los restantes temas tratados en el Proyecto se encuentran publicados en tres tomos de la colección La Seguridad Social en la Encrucijada, 2002, Universidad Nacional, Facultad de Ciencias Económicas, CID; Ministerio de Salud, Programa de Apoyo a la Reforma. La dirección del Proyecto estuvo a cargo de Óscar Rodríguez Salazar
} 
1999 (46\%deltotal) A precios del año 2000, el total de ingresos operacionales ascendió a \$4,54 billones en 1999 (15,6\% de incremento real). A partir del comportamiento de las 4 EPS tomadas como referencia (Sanitas, Humana Vivir, Coomeva y Famisanar), se concluye que una EPS cuyo negocio básico sea el aseguramiento en salud necesita un margen bruto de 17,2 \% para cubrir los gastos de operación y los no operacionales, y lograr un margen antes de impuestos de 1,1 \%.

Palabras Claves: seguro, gastos, costos de la atención en salud, servicios de salud, Colombia (fuente: DeCS, BIREME).

\section{ABSTRACT \\ Health insurance in the contributive and subsidized regimes and its impact on the service providers}

The performance of 18 private Health-promoting (EPS) and Family Compensation(CCF) entities, as well as their general balances for 1997, 1998 and 1999, were studied to determine the profit margins achieved by EPS's in their work of administering health insurance. The average behavior of each EPS balance sheet was analyzed to reduce the effect produced by extreme cases; each EPS's value was thus weighted by the number of its affiliated people. The expected behavior of the costs and expenses of companies whose main business is providing health insurance could thus become determined. The main source of operational income for a private EPS is the contributive regime's per capita unit of payment (UPC). Subsidized regime participation and that of other sources of income has decreased year by year. By contrast, public EPS's have shown decreasing participation in income obtained from UPC (contributive and subsidized) and growing dependence on other sources of income; this can be interpreted as being a symptom of weak commercial management. According to the balance sheets provided by the SNS, the EPS (public, private and Family Compensation entities), including the Social Security Institute (ISS), together obtained a total of 4,18 billion pesos operational income in 1999, an increase of 21,7\% as compared to 1998. Income received from the ISS amounted to $\$ 1,93$ billion in 1999 (46\% of the total). At 2000 prices, the total amount of operational income was \$ 4,54 billion pesos in 1999 (15,6\% real increase). Taking the behavior of 4 EPS's as our reference point (Sanitas, Humana Vivir, Coomeva and Famisanar), it can be concluded that an EPS whose main business is health insurance needs a $17,2 \%$ gross margin to cover its operational and non-operational costs and a 1,1\% margin before tax.

Key Words: Health insurance, health care costs, income, Colombia (source: MeSH, NLM).

L a Academia Nacional de Medicina solicitó al Centro de Investigaciones para el DesarrolloCID, de la Facultad de Ciencias Económicas, de la Universidad Nacional de Colombia, concepto sobre el margen que logran las Entidades Promotoras de Salud- EPS en su labor de administración de los recursos del Sistema General de Seguridad Social en Salud-SGSSS. La información acopiada y el análisis realizado por el grupo de investigación del Centro de Investigaciones para el Desarrollo, sobre régimen subsidiado sustentan el presente documento (1-3).

\section{MÉTODOS}

Se utilizó información de los estados de resultados y balances generales para 1997, 1998 y 1999 entregados a la Superintendencia Nacional de Salud-SNS por 18 EPS privadas y Cajas de 
Compensación Familiar-CCF. Por no contar con información oficial a Diciembre 31, no se incluyó el año 2000. Para disminuir el efecto de los casos extremos, el análisis se hizo sobre el comportamiento promedio de cada partida de resultados o de balance, para lo cual el valor de cada EPS se ponderó por el número de afiliados. Como Unimec mostró un comportamiento especial, los datos se analizaron sin dicha EPS. Adicionalmente, se muestra el comportamiento de 4 EPS privadas (Sanitas, Humana Vivir, Coomeva, Famisanar) cuyos ingresos, costos, gastos y resultados se derivan esencialmente de la actividad aseguradora en salud. Así se puede establecer el comportamiento esperado de los costos y gastos de una entidad cuyo negocio central sea el aseguramiento en salud. También es posible determinar el comportamiento que podría lograr el conjunto de las EPS analizadas al eliminar las distorsiones que puede generar el hecho de ser éste uno más de los negocios de una aseguradora o de una CCF (Tabla 1).

Tabla1. EPS examinadas en el estudio

\begin{tabular}{lll}
\hline \multicolumn{2}{c}{ EPS privadas y CCF } & EPS benchmark* \\
\hline Colmena & Comfenalco & Sanitas \\
Salud Total & Valle & Humana Vivir \\
Cafesalud & Saludcoop & Coomeva \\
Sanitas & Humana Vivir & Famisanar \\
Unimec & Colpatria & \\
Compensar & Coomeva & \\
Comfenalco Antioquia & Famisanar & \\
Susalud & SOS & \\
Colseguros & Cruz Blanca \\
& Solsalud & \\
& * Las EPS de benchmark forman parte del grupo de EPS privadas y CCF
\end{tabular}

\section{RESULTADOS}

El análisis realizado a la información de las Empresas Promotoras de Salud-EPS permite destacar los siguientes aspectos:

En el periodo de análisis (1997-1999) los ingresos operacionales de las EPS muestran tasas de crecimiento altas, lo cual se puede calificar de excepcional, en vista de las condiciones de recesión que enfrentó el país.

Las EPS privadas tienen como fuente principal de ingresos operacionales la Unidad de Pago por Capitación-UPC del régimen contributivo. La participación del régimen subsidiado y de las otras fuentes de ingresos es cada año menor. Por el contrario, las EPS públicas denotan una participación cada vez menor de los ingresos por UPC (contributiva y subsidiada) y una creciente dependencia de los otros ingresos, lo cual puede tomarse como síntoma de una gestión comercial débil.

A pesar de mostrar porcentajes de gastos de operación (administración y ventas) inferiores a las EPS públicas, las EPS privadas y las Cajas de Compensación Familiar-CCF, aunque en menor proporción, también enfrentaron pérdidas operacionales. 
A partir del comportamiento de las 4 EPS tomadas como referencia (Sanitas, Humana Vivir, Coomeva y Famisanar), se concluye que una EPS cuyo negocio básico sea el aseguramiento en salud necesita un margen bruto de 17,2 \% para cubrir los gastos de operación y los no operacionales, y lograr un margen antes de impuestos de 1,1\%.

Las EPS no enfrentaron dificultades en el recaudo de la UPC contributiva, pero sí serios inconvenientes para recuperar la cartera con el régimen subsidiado. Debido a esto y a la inversión de parte de los recursos disponibles para lograr rendimientos que permitan cubrir las pérdidas operacionales, las EPS presentan periodos de pago a las prestadoras relativamente altos, lo cual puede generar traumatismos financieros a las Instituciones Prestadoras de Servicios-IPS. Por ello es necesario que las IPS mejoren su proceso de facturación y su gestión de cobro y que los entes de control presionen la fluidez de los recursos del régimen subsidiado y garanticen la agilidad de los giros desde los entes territoriales a las aseguradoras y de éstas a las IPS.

\section{NUMERO DE AFILIADOS}

Para comprender mejor el comportamiento de los ingresos, costos y gastos de las EPS, en la Tabla 2 se muestra el número total de afiliados por tipo de EPS. El grupo conformado por las EPS privadas y CCF logra crecimientos importantes en este aspecto, a costa de la pérdida de participación del grupo de EPS públicas. El número de afiliados, en el total, en el ISS y en las restantes EPS públicas, decrece entre 1997 y 1999.

En 1999, el 23,7 \% del total de afiliados de las EPS no públicas (EPS privadas y CCF) corresponden a Unimec (1 487 692) y el 22,9 \% a Saludcoop (1 436 685). Las dos concentran el 46,6 \% de la afiliación de este grupo de EPS. Excluido Unimec, el total de afiliados de las EPS no públicas queda en 3628756 para 1997, en 4236208 para 1998 y en 4793715 para 1999. 
Tabla 2. Total afiliados por tipo de EPS

\begin{tabular}{|c|c|c|c|c|c|c|}
\hline Tipo de EPS & No & 1997 & 1998 & 1999 & $\begin{array}{c}\text { \% var. } \\
98\end{array}$ & $\begin{array}{c}\text { \% var. } \\
99\end{array}$ \\
\hline ISS & & 7584138 & 6583034 & 5927920 & $-13,2$ & $-10,0$ \\
\hline EPS públicas & 10 & 3810279 & 3430853 & 3504728 & $-10,0$ & $+2,1$ \\
\hline EPS privadas y & 18 & 5051721 & 5895547 & 6281407 & $+16,7$ & $+6,5$ \\
\hline CCF & 29 & 16446138 & 15909434 & 15714055 & $-3,3$ & $-1,2$ \\
\hline $\begin{array}{l}\text { Total EPS } \\
\text { EPS benchmark }\end{array}$ & 4 & 1264898 & 1627087 & 1807303 & $+28,6$ & $+11,1$ \\
\hline $\begin{array}{l}\% \text { participación } \\
\text { frente al total }\end{array}$ & & 46,1 & 41,4 & 37,7 & & \\
\hline ISS & 10 & 23,2 & 21,5 & 22,3 & & \\
\hline EPS públicas & 18 & 30,7 & 37,1 & 40,0 & & \\
\hline $\begin{array}{l}\text { EPS privadas y } \\
\text { CCF } \\
\text { EPS benchmark }\end{array}$ & 4 & 7,7 & 10,2 & 11,5 & & \\
\hline
\end{tabular}

\section{RESULTADOS GLOBALES DE LAS EPS}

El ingreso operacional de las EPS está constituido por la suma de ingresos procedentes de la UPC del régimen contributivo, la UPC del régimen subsidiado, los planes complementarios de saludPAC, los servicios de salud prestados directamente por las EPS, las cuotas moderadoras, copagos, afiliación y exámenes de admisión, los recobros (Seguro Obligatorio de Accidentes de Tránsito, Administradoras de Riesgos Profesionales, otras EPS), otros conceptos (no especificados en los estados de resultados) y por el ajuste por inflación (éste dejó de aplicarse para las cuentas de resultados en 1999).

De acuerdo con los estados de resultados suministrados por la SNS, incluido el ISS, las EPS (públicas, privadas y CCF) lograron un total de ingresos operacionales de \$2,72 billones (millón de millones) en 1997, \$3,31 billones en 1998 y \$ 4,18 billones en 1999, lo cual significa un incremento de 21,7 \% en 1998 y de 26,3 \% en 1999. Los ingresos del ISS fueron de \$1,53 billones en 1997 (56 \% del total), \$ 1,57 billones en 1998 (47\%) y \$ 1,93 billones en 1999 (46\%). A precios del año 2000, el total de ingresos operacionales ascendió a \$ 3,77 billones en 1997, \$ 3,93 billones en 1998 (crecimiento real de 4,3\%) y \$4,54 billones en 1999 (15,6 \% de incremento real). Los ingresos de las EPS crecieron por encima de la inflación y a tasas que pueden calificarse como excepcionalmente altas, máxime cuando se logran en un periodo de recesión económica. Bavaria, una de las empresas más sólidas del país, incrementó sus ingresos operacionales, a precios corrientes, en 16,7 \% en 1998 (apenas la inflación) y en 1,5 \% en 1999 (menos que la inflación), por debajo del incremento logrado por las EPS.

El porcentaje de gastos de operación (administración y ventas) de las EPS públicas desborda al mostrado por las otras EPS. Por no contar con información detallada no fue posible profundizar en las causas de esta situación, pero parte del problema se debe a los mayores costos laborales que tienen estas EPS. En 1997 el grupo de las EPS públicas (sin ISS) incurre en gastos de operación 
(administración y ventas) equivalentes al 65,3 \% de sus ingresos y sufre una pérdida operacional de $12 \%$. Esto significa que por cada cien pesos de ingreso operacional (total devengado por UPC contributiva y subsidiada, por el programa anual de caja-PAC, por recobros, por servicios de salud y otros conceptos relacionados con su objeto social), en 1997 las EPS públicas tienen \$ 65 de gastos de administración y ventas y \$ 12 de pérdida operacional. En 1999, los gastos de operación representan 56,5 \% de los ingresos y la pérdida operacional asciende a 21,9 \%. Es decir, el monto de sus costos y gastos de administración y ventas equivale a 1,22 veces sus ingresos operacionales. De acuerdo con esto, las EPS públicas necesitan incrementar en forma significativa el monto de sus ingresos, o reducir de manera drástica sus costos y sus gastos de operación para ser viables.

Aun cuando su porcentaje de costos es superior al de las EPS públicas, las EPS privadas y CCF presentan proporciones de gastos de operación (administración y ventas) y de pérdidas operacionales menores. En 1997 los gastos de operación representan 20,1 \% de los ingresos operacionales y la pérdida operacional 1,5 \%. En 1999 los gastos bajan a 19,7 \% y la pérdida operacional a $0,8 \%$.

Las EPS (públicas, privadas y CCF, incluido ISS) presentan un resultado operacional (ingresos menos costo de prestación del servicio médico menos gastos de administración y ventas) negativo en \$ 44 millardos (mil millones) en 1997, \$ 543 millardos en 1998 y \$ 298 millardos en 1999. La pérdida operacional del ISS fue de \$ 16 millardos en 1997 (37\% de la pérdida operacional total), \$ 412 millardos en 1998 (76 \%) y \$ 140 millardos en 1999 (47\%).

Las EPS privadas y las CCF también muestran un resultado operacional negativo de \$12 millardos en 1997 (28 \% de la pérdida operacional total), \$ 28 millardos en 1998 (5 \%) y de \$ 12 millardos en 1999 (4 \%). Unimec presenta una pérdida operacional de \$ 3 millardos en 1997, \$ 9 millardos en 1998 y \$ 14 millardos en 1999. Sin Unimec, las pérdidas operacionales de las 17 restantes EPS no públicas se reducen a \$ 9 millardos en 1997 y a \$ 19 millardos en 1998. Para 1999 logran una utilidad operacional cercana a $\$ 2$ millardos.

En 1999 el grupo de 18 EPS privadas y CCF, por cada cien pesos de ingreso operacional, tuvo 8,9 pesos de gastos de personal de administración y ventas y 10,8 pesos de otros gastos de operación (honorarios, comisiones, impuestos, contribuciones, arrendamientos, seguros, publicidad, provisiones, depreciaciones, ajustes por inflación y otros) y 18,4 \% de total de gastos operacionales. El 42 \% de los gastos de operación corresponde a personal.

En el nivel de resultado neto (resultado operacional mas ingresos no operacionales menos gastos no operacionales mas corrección monetaria menos provisión para impuesto), el total de EPS presenta una pérdida de \$ 61 millardos en 1997, \$ 468 millardos en 1998 y \$ 213 millardos en 1999. La participación del ISS en esa pérdida es de 77 \% en 1997 (\$ 47 millardos), 93 \% en 1998 (\$ 463 millardos) y 64 \% en 1999 (\$ 137 millardos).

Las EPS privadas y CCF muestran una pérdida neta de \$ 6 millardos en 1997 (10 \% de la pérdida neta total), \$ 12 millardos en 1998 (2\%) y \$ 4 millardos en 1999 (2\%). Unimec logró utilidad después de impuestos de $\$ 1,3$ millardos en 1997, pero sufrió pérdidas netas de \$10 millardos en 1998 y de \$ 25 millardos en 1999. Así, las EPS privadas y CCF, sin Unimec, arrojan una pérdida neta de \$ 7 millardos en 1997, de \$2 millardos en 1998 y una utilidad de \$ 21 millardos en 1999. 


\section{INGRESO OPERACIONAL PROMEDIO PONDERADO DE UNA EPS PRIVADA}

La Figura 1 muestra el ingreso operacional promedio (ponderado por número de afiliados) logrado por el grupo de las 18 EPS analizadas, con y sin Unimec y por las 4 EPS privadas tomadas como parámetro de comparación (benchmark), en millardos de pesos, para 1997, 1998 y 1999, a precios del año 2000.

A precios de 2000, las EPS privadas y CCF muestran un crecimiento sostenido en el monto promedio de los ingresos operacionales. Este aumentó cerca de 29 \% en 1998 y 9 \% en 1999 para el total de las EPS privadas y CCF, incluido Unimec. El monto del ingreso promedio ponderado sin Unimec es menor, como se observa en la Figura 1, pero la dinámica de crecimiento mejora, dado que el ingreso operacional promedio ponderado aumentó $30 \%$ en 1998 y 31 \% en 1999. Las 4 EPS tomadas como parámetro de comparación (benchmark) presentan un aumento en su ingreso operacional promedio ponderado de 67 \% en 1998 y de 23 \% en 1999.

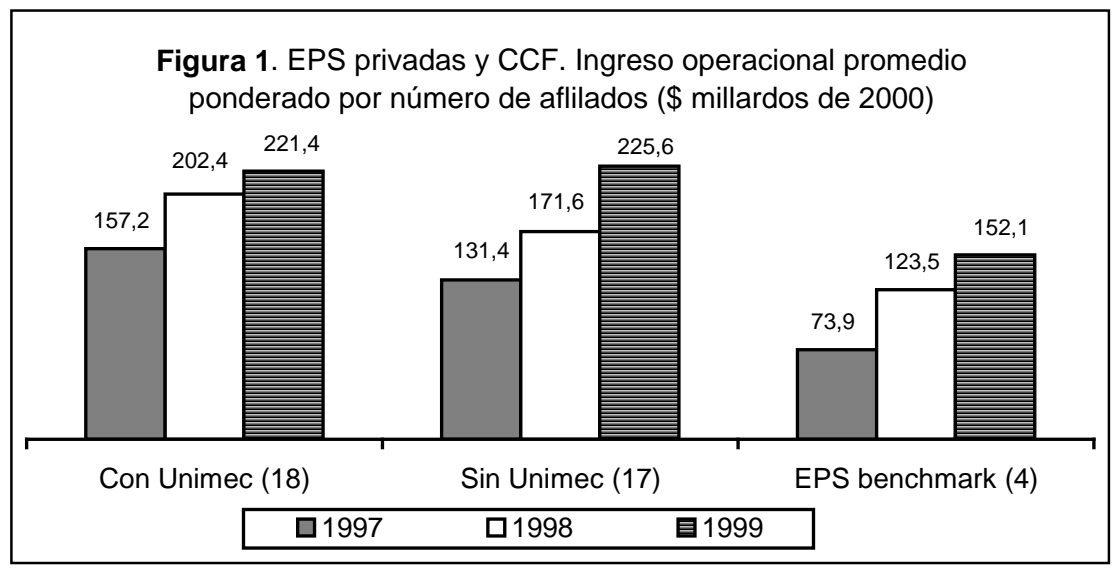


La Figura 2 muestra la participación de las principales fuentes en el total de ingresos para cada grupo y año de análisis. Para facilitar su representación gráfica, las fuentes de ingresos se agrupan en tres: UPC contributivo, UPC subsidiado y otros ingresos (incluye Programa Anual de Caja, servicios de salud, cuotas moderadoras, copagos, afiliación, exámenes de admisión, recobros, otros conceptos y ajuste por inflación).

En el promedio ponderado de las 18 EPS privadas y CCF, incluida Unimec, se observa una participación creciente de los ingresos por UPC del régimen contributivo que pasa del $54 \%$ en 1997, al 72 \% en 1999. La participación de los ingresos por UPC del régimen subsidiado muestra tendencia decreciente, pues en 1997 fue de $37 \%$ y en 1999 cae al 24 \%. La participación de los otros ingresos también cae en el periodo (9 \% en 1997, 4 \% en 1999). 


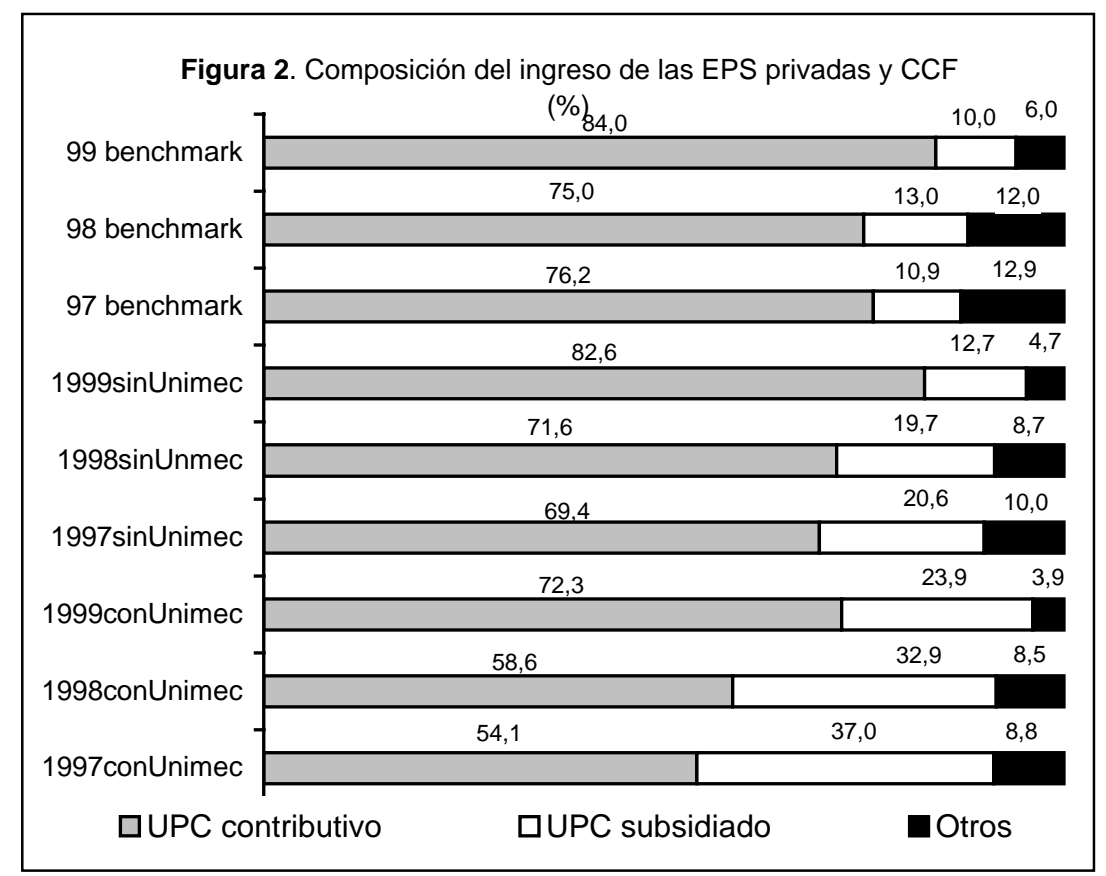

Sin Unimec, las participaciones pasan de 69 \% en 1997 a 83 \% en 1999 para el ingreso por UPCC, de $21 \%$ a $13 \%$ para la UPC-S y de $10 \%$ a $5 \%$ para los otros ingresos. Esto refleja la fuerte influencia de Unimec en los promedios de las EPS privadas y CCF.

Los ingresos operacionales de Unimec, a precios de 2000, fueron de \$ 218 millardos (mil millones) en 1997 (28 \% de UPC-C, 65 \% de UPC-S y $7 \%$ de otros ingresos), \$ 284 millardos en 1998 (37 \% de UPC-C, 55 \% de UPC-S y 8 \% de otros ingresos) y \$ 233 millardos en 1999 (38\% de UPC-C, 60\% de UPC-S y $2 \%$ de otros ingresos), con un incremento de $30 \%$ en 1998 y una disminución de 18 \% en 1999.

En 1999 Unimec mostró un margen bruto de 16,1 \% del ingreso operacional, gastos de personal de administración y ventas por $8,5 \%$, total de gastos operacionales por $22,4 \%$, pérdida operacional por $6,3 \%$, ingresos no operacionales (rendimientos y otros) por $2,7 \%$, gastos no operacionales por 7,4 \% y pérdida neta por 11,8 \%. Al contrario de las otras EPS privadas y CCF objeto de estudio, Unimec tenía una fuerte dependencia de los recursos del régimen subsidiado y un comportamiento atípico que distorsiona los promedios del grupo. Por ello, en los cálculos hechos para este concepto se excluyen los datos de esa EPS.

El promedio de las 4 EPS tomadas como parámetro refleja la UPC-C como fuente básica de los ingresos operacionales, con una participación del 84 \% en el total para 1999. La participación de la UPC-S es de sólo $10 \%$ y la de los otros ingresos el $8 \%$. 


\section{MARGEN BRUTO DE LAS EPS}

Margen bruto es la proporción de ingresos operacionales con que cuenta la EPS para cubrir sus gastos operacionales (de administración y ventas) y financieros y para generar utilidad o excedente. Se calcula dividiendo la utilidad bruta por los ingresos operacionales. La utilidad bruta es la diferencia entre el ingreso operacional y el costo de prestación de los servicios de salud a los afiliados. La Figura 3 muestra el promedio ponderado (por número de afiliados) del costo de prestación del servicio de salud como proporción del ingreso operacional y el margen bruto que obtiene la EPS en el manejo de los recursos del sistema.

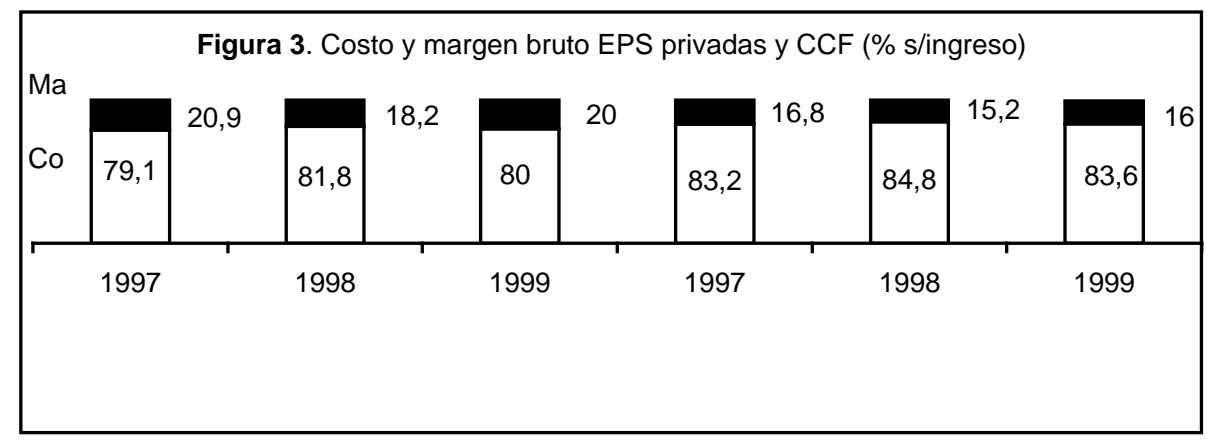

Sin Unimec, el costo promedio de prestación del servicio representó $79 \%$ del ingreso operacional de las EPS no públicas (privadas y CCF) en 1997 y 80 \% en 1999. Esto significa que en 1999 por cada cien pesos de ingreso operacional las EPS privadas y CCF incurrieron en 80 pesos de costo y lograron una utilidad bruta de 20 pesos. Las 4 EPS tomadas como parámetro de comparación (benchmark) presentan una proporción de costo mayor y un margen bruto menor que el resto de las EPS analizadas. Así, en 1999 por cada cien pesos de ingresos operacionales, estas EPS incurrieron en costos de prestación del servicio de salud por 84 pesos y les quedan 16 pesos para cubrir sus gastos de operación, sus gastos financieros y para lograr una utilidad o excedente que permita realizar inversiones, pagar sus obligaciones financieras y retribuir a sus propietarios.

La Figura 4 muestra el costo del plan obligatorio de salud (POS-C y POS-S) como proporción del ingreso por UPC-C y UPC-S y el margen bruto que obtienen las EPS privadas y CCF, sin Unimec, en la administración de los recursos del sistema. En 1999 estas EPS, por cada cien pesos de ingresos por UPC-C, incurrieron en 84 pesos de costo de atención a sus afiliados y lograron 16 pesos de utilidad bruta en el RC. En el RS estas EPS incurrieron en 85 pesos de costo y lograron 15 pesos de utilidad bruta por cada cien pesos de ingreso por UPC-S. En el RS, el creciente uso del servicio por parte de los afiliados y la congelación del valor de la UPC-S en 1999 genera un porcentaje de costo ascendente y un margen decreciente. 


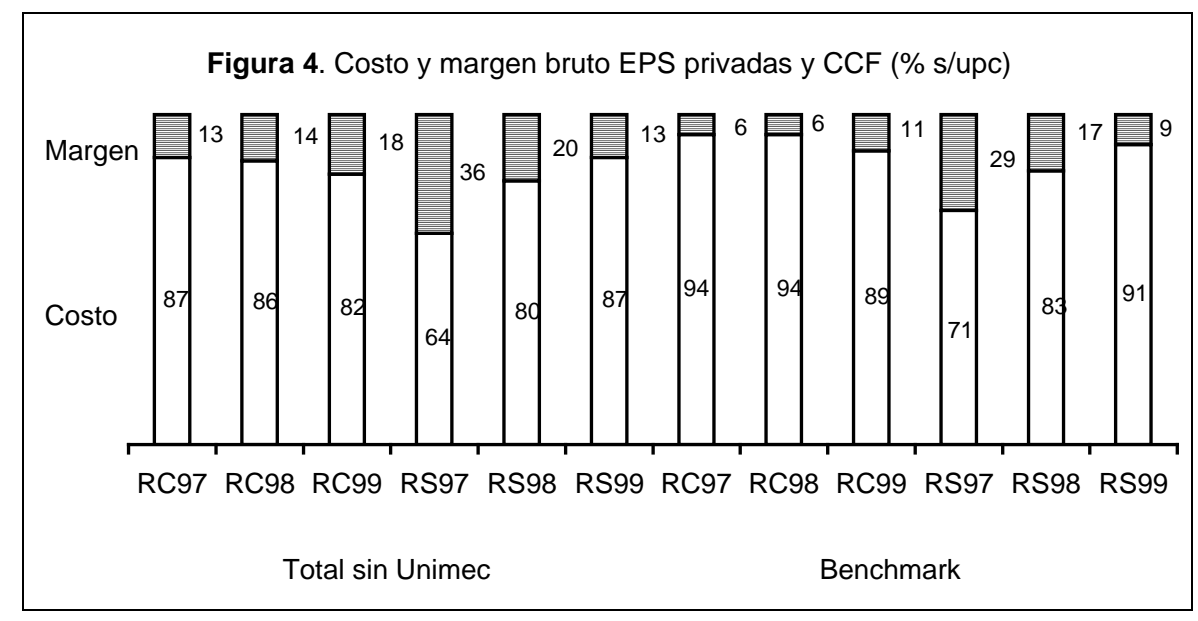

La Tabla 3 muestra la evolución del valor promedio ponderado de la Unidad de Pago por Capitación UPC establecida por el Consejo Nacional de Seguridad Social en Salud CNSSS para el proceso de compensación en los dos regímenes (contributivo y subsidiado). La UPC-S fue equivalente al 62\% de la UPC-C en 1997 y 1998. Esa equivalencia cae al 53.2\% a partir de 1999. Para las promotoras cuyos ingresos dependan en forma significativa de la UPC-S, esto incide negativamente en los resultados.

Tabla 3. Evolución del valor promedio ponderado de la UPC

\begin{tabular}{|c|c|c|c|c|c|}
\hline Año & UPC-C & UPC-S & $\begin{array}{c}\text { UPC-S/UPC- } \\
\text { C }\end{array}$ & \%var.UPC-C & \%var.UPC-S \\
\hline 1997 & 174989 & 108464 & 62,0 & - & - \\
\hline 1998 & 207362 & 128530 & 62,0 & 18,5 & 18,5 \\
\hline 1999 & 241577 & 128530 & 53,2 & 16,5 & 0 \\
\hline 2000 & 265734 & 141480 & 53,2 & 10,0 & 10,0 \\
\hline
\end{tabular}

La Figura 5 muestra el monto promedio de utilidad bruta lograda por el grupo de las EPS privadas y CCF sin Unimec (en millardos de pesos del año 2000). 


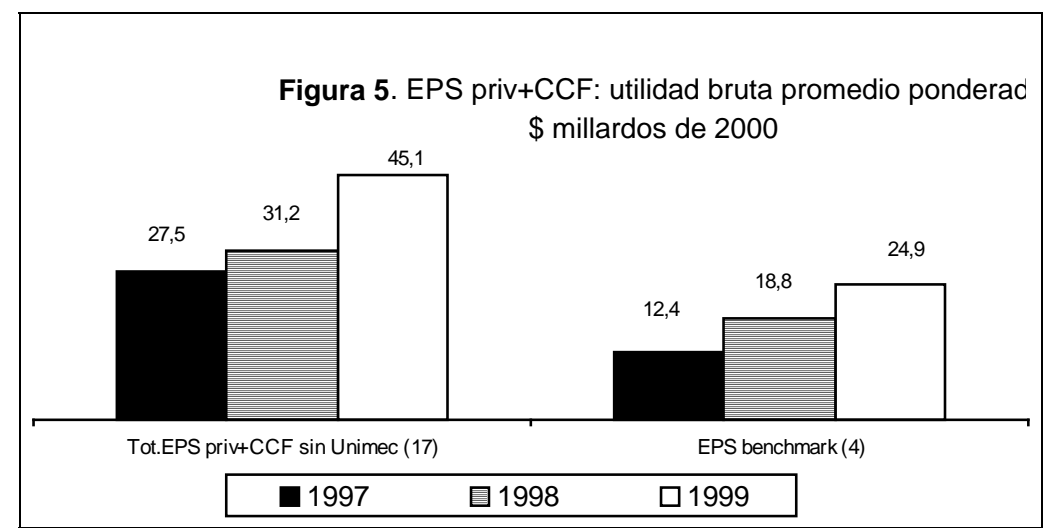

\section{¿ES SUFICIENTE EL MARGEN BRUTO?}

Según los estados de resultados entregados a la SNS por las EPS analizadas, el margen bruto logrado en su actividad de aseguramiento en salud es insuficiente para cubrir los gastos operacionales (de administración y ventas) en que incurren. Como se observa en la Figura 6, el monto promedio ponderado (por número de afiliados) de los gastos operacionales supera la utilidad bruta de las EPS y produce un resultado operacional (ingresos operacionales menos costos y gastos de operación) negativo, a nivel total. Esto se debe a que los costos y gastos crecen más que los ingresos. Las EPS de comparación presentan pérdida operacional en 1997 y 1998 y utilidad en 1999. 


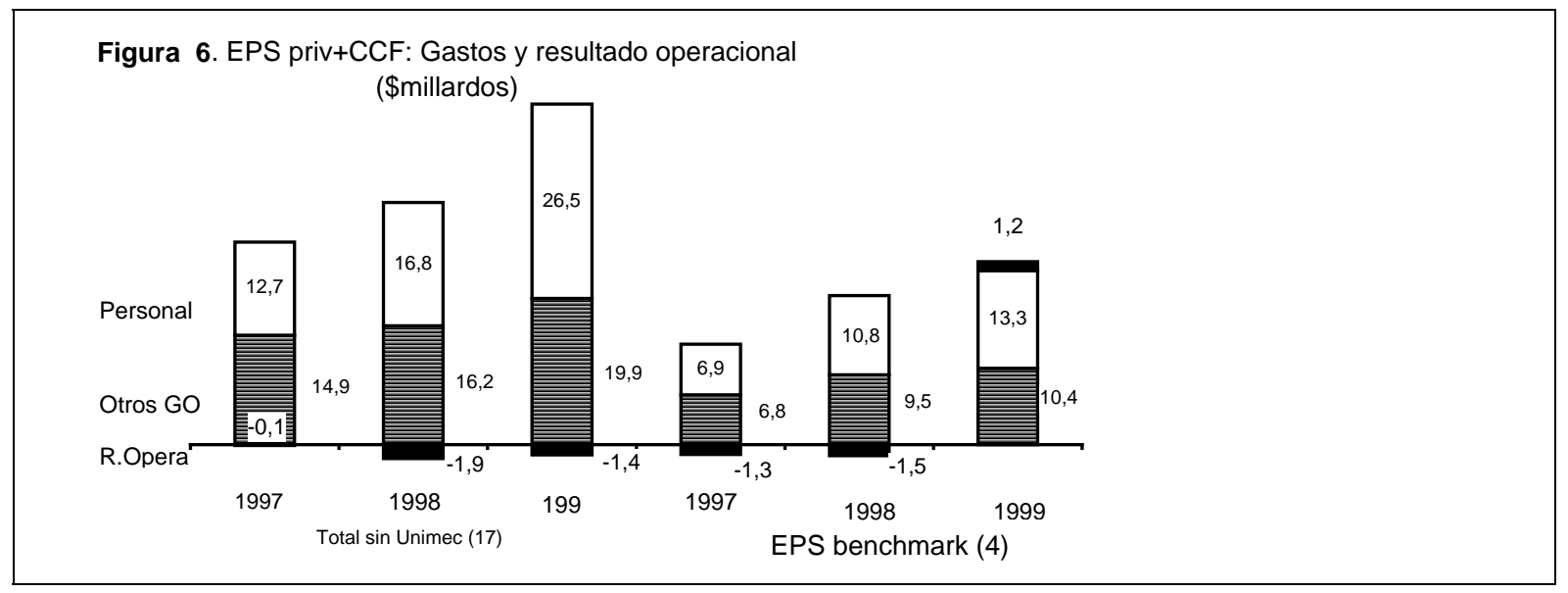

El grupo de 17 EPS no públicas (EPS privadas y CCF), sin Unimec, presenta una pérdida operacional promedio de \$ 126 millones en 1997, de \$ 1,9 millardos (mil millones) en 1998 y de \$ 1,4 millardos en 1999. El grupo de 4 EPS de comparación muestra pérdida operacional promedio de \$ 1,3 millardos en 1997 y de \$ 1,5 millardos en 1998. En 1999 este grupo arroja utilidad operacional promedio de $\$ 1,2$ millardos y utilidad neta de $\$ 647$ millones.

El porcentaje (frente al ingreso operacional) de los gastos de operación o del resultado operacional no muestra un comportamiento consistente con el concepto de economía de escala, pues mientras Comfenalco Valle, a vía de ejemplo, con 119 mil afiliados tiene 13,6 \% de gastos operacionales -GO y 3,8 \% de utilidad operacional, Colmena, con 272 mil afiliados incurre en $24 \%$ de GO y en 0,4 \% de pérdida operacional y Saludcoop, con 1,4 millones de afiliados, muestra 23,3 $\%$ de GO y pérdida operacional de 1,1\%. Para 1999, los menores porcentajes de gastos operacionales se observan en Sanitas (8,3 \% con 201 mil afiliados), Comfenalco Antioquia (9,1 \% con 160 mil), Famisanar (10,9 \% con 516 mil), Compensar (12,8 \% con 259 mil) y Comfenalco Valle (13,6 \% con 119 mil afiliados).

Lo anterior sugiere que las EPS cuya operación está concentrada geográficamente son más eficientes e incurren en menores porcentajes de gastos de administración y ventas. Se observan, en este caso, economías de densidad.

Debido a que los ingresos no operacionales (rendimientos y otros) superan a los gastos no operacionales (financieros y otros), el resultado neto (después de impuestos) es positivo en todas las EPS, excepto en Unimec, que perdió 25208 millones y Colseguros, que perdió \$ 877 millones. Como se observa en la Tabla 4, en 1999 las 17 EPS privadas y CCF analizadas, sin Unimec, 
presentaron un monto de utilidades de \$ 21463 millones, para un promedio de \$ 1263 millones y un máximo de \$ 3732 millones logrado por SOS.

Tabla 4. EPS analizadas: número de afiliados, \%GO, MO, $\%$ YNO, \%GNO y MN en 1999

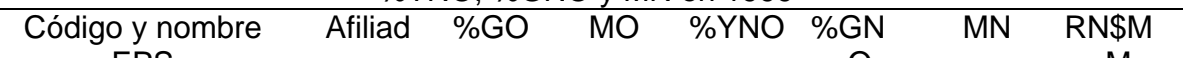

$\mathrm{O} M$




\begin{tabular}{|c|c|c|c|c|c|c|c|}
\hline Colpatria & 58 & 22.0 & -0.3 & 8.5 & 1.3 & 3.0 & 372 \\
\hline Solsalud & 67 & 14.0 & -1.2 & 4.5 & 2.0 & 1.0 & 143 \\
\hline Colseguros & 110 & 28.7 & -6.5 & 6.2 & 1.5 & -3.4 & -877 \\
\hline Confenalco Valle & 119 & 13.6 & 3.8 & 0.5 & 0 & 4.7 & 1475 \\
\hline Humana Vivir & 145 & 17.4 & 0 & 4.0 & 0.6 & 1.6 & 461 \\
\hline Comfenalco Antio- & 160 & 9.1 & 1.2 & 5.0 & 0 & 5.3 & 1693 \\
\hline quia & 174 & 17.6 & 4.0 & 3.6 & 0 & 7.4 & 3732 \\
\hline SOS & 201 & 8.3 & -1.6 & 2.5 & 0.7 & 0.1 & 78 \\
\hline Sanitas & 230 & 25.4 & 5.8 & 1.1 & 2.4 & 5.3 & 3348 \\
\hline Salud Total & 259 & 12.8 & -2.5 & 4.4 & 0 & 1.9 & 1546 \\
\hline Compensar & 272 & 24.0 & -0.4 & 2.0 & 1.0 & 1.6 & 900 \\
\hline Colmena & 476 & 27.7 & 2.6 & 2.4 & 1.4 & 4.7 & 2729 \\
\hline Cruz Blanca & 504 & 20.0 & -2.5 & 4.7 & 1.2 & 1.7 & 2032 \\
\hline Susalud & 516 & 10.9 & -0.4 & 1.2 & 0.5 & 0.2 & 213 \\
\hline Famisanar & 557 & 20.9 & 2.9 & 1.0 & 1.0 & 2.2 & 2053 \\
\hline Cafesalud & 946 & 17.5 & 1.3 & 0.8 & 1.9 & 0.5 & 931 \\
\hline Coomeva & 1437 & 23.3 & -1.1 & 3.5 & 2.5 & 0.2 & 634 \\
\hline Saludcoop & 6231 & 19.6 & 0.3 & 2.6 & 1.4 & 1.6 & 21463 \\
\hline \multicolumn{8}{|l|}{ Total sin Unimec } \\
\hline \multicolumn{8}{|l|}{ Coefic.correlac.s/ } \\
\hline Mínimo & 58 & 8.3 & -6.5 & 0.5 & 0 & -3.4 & -877 \\
\hline Máximo & 1437 & 28.7 & 5.8 & 8.5 & 2.5 & 7.4 & 3732 \\
\hline Promedio & 367 & 18.4 & 0.3 & 3.3 & 1.1 & 2.2 & 1263 \\
\hline Mediana & 230 & 17.6 & -0.3 & 3.5 & 1.0 & 1.7 & 931 \\
\hline
\end{tabular}

$\mathrm{GO}=$ Gastos operacionales, $\mathrm{MO}=$ Margen operacional $(\mathrm{RO} / \mathrm{Y})$, $\mathrm{YNO}=$ Ingresos no operacionales, $\mathrm{GNO}=\mathrm{Gastos}$ no operacionales, $\mathrm{MN}=$ Margen neto $(\mathrm{RN} / \mathrm{Y}), \mathrm{RN}=$ Resultado neto en \$millones, $\mathrm{Y}=$ Ingreso operacional. Afiliados en miles

La Figura 7 muestra el peso porcentual, frente al total de ingresos operacionales, de los gastos de personal, de los otros gastos de operación (administración y ventas) y del margen operacional para 17 EPS privadas (sin Unimec) y 4 EPS (Sanitas, Humana Vivir, Coomeva y Famisanar) tomadas como patrón de comparación (benchmark). El porcentaje de gastos de operación con respecto al ingreso operacional muestra una evolución interesante en el periodo analizado, pues desciende en 1998 y crece en 1999. Esto se debe a que en 1998 los ingresos de las EPS se incrementaron a tasas superiores a las de sus gastos, mientras en 1999 los gastos se incrementan en proporciones mayores a los ingresos, debido a la congelación del valor de la UPC-S en dicho año.

En 1997, en el grupo de las 17 EPS privadas y CCF (sin Unimec), los gastos de personal administrativo y de ventas equivalen, en promedio, a 11,4 \% del ingreso operacional y los otros gastos de operación (honorarios, comisiones, arrendamientos, seguros, publicidad, depreciaciones, provisiones y otros) a 9,7 \%, para un total de 21,1\%. Es decir, por cada cien pesos de ingreso operacional, el grupo de EPS privadas y CCF, incurre en 21 pesos de gastos de operación. Como ese grupo muestra un costo de atención al afiliado de 79,1 \%, ese año sufre una pérdida operacional de $0,1 \%$. Para 1998, los gastos operacionales del grupo son 19,2 \% y la pérdida operacional 1,1 \%. En 1999, esos porcentajes son 20,6 \% de gastos operacionales y 0,6 \% de pérdida operacional. 


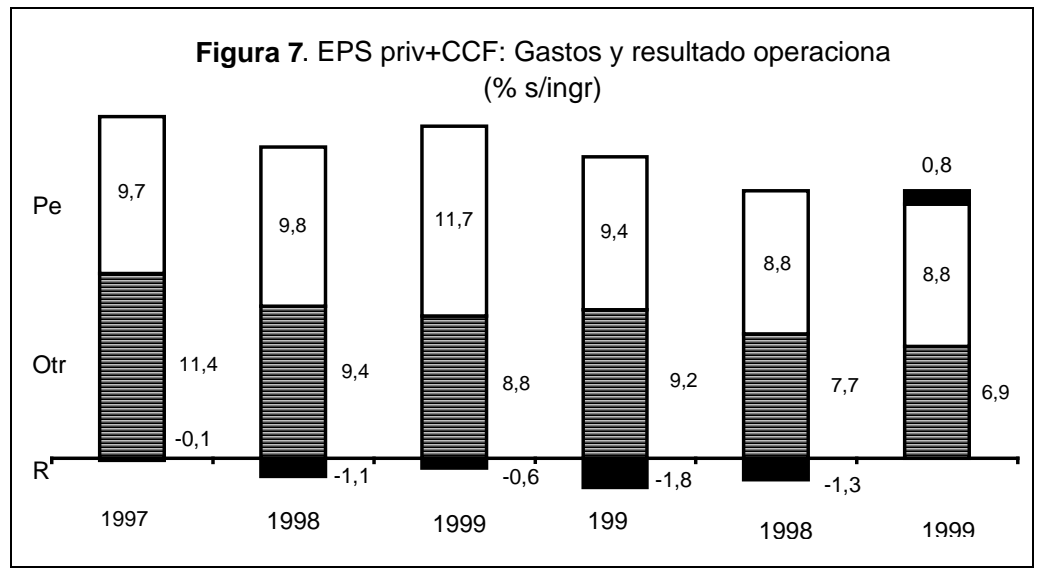

El promedio ponderado (por número de afiliados) del grupo de referencia (benchmark), muestra tendencia decreciente en el porcentaje promedio de gastos de operación, pues pasa de $9,2 \%$ en 1997 a 6,9 \% en 1999 en los gastos de personal administrativo y de ventas, de 9,4 \% a 8,8 \% en los otros gastos de operación y de 18,6 \% a 15,6 \% en el total de gastos de operación. El resultado operacional representa, en este caso, una pérdida de 1,8 \% en 1997 y de 1,3\% en 1998 y una utilidad de $0,8 \%$ en 1999. El comportamiento porcentual de los gastos operacionales de este grupo se toma como parámetro en el siguiente título, para determinar un margen bruto que le permita a las EPS adelantar sus actividades comerciales y administrativas de manera apropiada.

\section{MARGEN BRUTO NECESARIO PARA OPERAR}

En vista de que la administración de la salud es un negocio de volumen, en el cual la rentabilidad se logra más por rotación que por margen, es posible determinar el margen bruto a lograr, por sumatoria de los porcentajes aceptados como normales para los gastos de operación (administración y ventas), los gastos no operacionales y la utilidad. La tabla 5 presenta, para 1999, los gastos operacionales (administración y ventas), los ingresos y los gastos no operacionales, como proporción de los ingresos operacionales de las EPS analizadas.

Tabla 5. Gasto como proporción del ingreso operacional 1999 


\begin{tabular}{lrr}
\multicolumn{1}{c}{ (sin Unimec) } & & \\
\hline \multicolumn{1}{c}{ Concepto } & $\begin{array}{c}\text { EPS } \\
\text { priv+CCF }\end{array}$ & $\begin{array}{c}\text { EPS } \\
\text { benchmark }\end{array}$ \\
\hline Gastos operacionales (admon y & 20,6 & 15,6 \\
ventas) & $-2,8$ & $-1,0$ \\
Ingresos no operacionales & 1,9 & 1,5 \\
Gastos no operacionales & 19,7 & 16,1 \\
Total & & \\
\hline
\end{tabular}

Las 4 EPS privadas (Sanitas, Humana Vivir, Coomeva y Famisanar) tomadas como referencia (benchmark) tienen como negocio central el aseguramiento en salud. Como tal, las proporciones de gastos operacionales (administración y ventas), de ingresos y de egresos no operacionales mostrados para ellas en la tabla 10 se pueden aceptar como normales. Así, una EPS requeriría 16,1 \% del ingreso operacional como margen bruto para cubrir sus gastos de operación (administración y ventas) y sus gastos no operacionales, pero sin tener ni utilidad ni pérdida. Esta es una simplificación, porque no toma en cuenta el comportamiento de los gastos frente al volumen de actividades, pero sirve para sugerir, de manera aproximada, un margen normal para las EPS antes de impuestos y utilidad.

En 1999 las EPS no públicas (privadas y CCF), sin Unimec, logran una rotación de activos de 2,7 veces (por cada peso invertido en activo total la EPS logra tres pesos de ingreso operacional) y una rotación de patrimonio de 18,4 veces (por cada peso que los dueños mantienen en la EPS como patrimonio, ésta logra 18,4 pesos de ingreso operacional). Para el mismo año, las EPS tomadas como parámetro (benchmark) son más eficientes en el uso de los recursos, pues logran una rotación del activo de 4,4 veces (4,4 pesos de ingreso operacional por cada peso invertido en activo total) y una rotación de patrimonio de 20,9 veces (21 pesos de ingreso operacional por cada peso de patrimonio).

El impuesto a la renta que muestran las EPS analizadas en su estado de resultados para 1999 es mínimo (0,1\% del ingreso operacional) y se compensa con la utilidad por corrección monetaria (0,3\% para el total sin Unimec, 0,2\% para las EPS de benchmark). Como tal, se puede desestimar para el cálculo del margen necesario para operar.

Los Depósitos a términos fijos-DTF estuvieron en el país estuvo alrededor del 12,8 \% (El Tiempo, viernes 27 de abril de 2001, p.1-10). Si se liquidaran las EPS y los activos se pudieran realizar al valor que refleja el balance, los dueños podrían disponer del monto patrimonial para realizar nuevas inversiones, por ejemplo en Certificados de Depósito a Término, con el rendimiento indicado. Para mantenerse en el negocio de aseguramiento en salud, es posible que el inversionista exija una prima de riesgo de, por ejemplo $10 \%$. Como tal, la EPS debe garantizar un rendimiento patrimonial de por lo menos 22,8 \% (12,8 \% de DTF + $10 \%$ de prima de riesgo). A partir de la fórmula de rentabilidad patrimonial y con las anteriores premisas se puede calcular el margen neto antes de impuestos a lograr por la EPS, así:

$\mathrm{ROE}=\mathrm{RAT} / \mathrm{K}=(\mathrm{RAT} / \mathrm{Y}) \times(\mathrm{Y} / \mathrm{K})=$ MAT $\mathrm{x}$ Rot_K

MAT $=$ ROE / Rot_K 
Donde:

$\mathrm{ROE}=$ rentabilidad del patrimonio (en este caso antes de impuesto)

RAT= resultado (utilidad o pérdida) neta antes de impuesto

$\mathrm{K}=$ patrimonio total

$\mathrm{Y}=$ ingreso operacional

MAT= margen antes de impuesto (RAT/Y)

Rot_K= rotación del patrimonio, o veces que se vende el patrimonio (Y/K)

Con base en lo anterior, el margen neto antes de impuestos a reconocer a una EPS cuyo negocio básico sea el aseguramiento en salud sería de 1,1 \% (22,8/20,9). Como tal, el margen bruto a lograr por la EPS sería de 17,2 \% (16,1 \% para cubrir los gastos de operación y los no operacionales y 1,1 $\%$ de margen antes de impuestos). La tabla 6 muestra la composición del margen bruto calculado.

Tabla 6. Margen bruto a lograr por las EPS (\% s/ingr)

\begin{tabular}{lr}
\hline \multicolumn{1}{c}{ Concepto } & $\%$ \\
\hline Gastos operacionales (de administración y & 15,6 \\
ventas) & $-1,0$ \\
Ingresos no operacionales & 1,5 \\
Gastos no operacionales & 1,1 \\
Resultado antes de impuestos & 17,2 \\
Margen bruto esperado & \\
\hline
\end{tabular}

\section{ROTACIÓN DE CUENTAS POR COBRAR Y PROVEEDORES}

El flujo de recursos entre los distintos actores que intervienen en el SGSSS (patronos o entes territoriales - EPS/ARS - IPS) es uno de los problemas que más inciden en los resultados y en la sosteniblidad del sistema. Los prestadores (IPS) afirman que las promotoras (EPS o ARS) demoran demasiado el pago por los servicios de salud prestados y que esto genera dificultades financieras que pueden restarle viabilidad a su operación, en detrimento del usuario, objeto final del SGSSS.

La rotación de cartera (periodo de cobro) indica el número de días que se toman los patronos en el RC o los entes territoriales en el RS para cancelar sus compromisos con las EPS por concepto de aportes o UPC-S. Se calcula dividiendo el saldo de las cuentas deudoras por el promedio diario de ingresos operacionales [Deudores/(Y/d)].

Las EPS no enfrentan dificultades para recaudar los aportes de los patronos y trabajadores. De acuerdo con los balances, el monto de las cuentas por cobrar del régimen contributivo no representa más de seis días de ingresos de UPC contributivo. En cambio, en el régimen subsidiado se perciben serios inconvenientes con el desembolso de la UPC-S. Los montos por cobrar por UPC-S registrados en los balances crecen de manera sostenida y su rotación en días (periodo de cobro) alcanza, en 1999, 231 días en las EPS públicas, 190 días en las EPS privadas y CCF (incluida Unimec), 215 días sin Unimec y 89 días en las EPS tomadas como referencia. Periodos tan altos 
pueden atrasar los pagos a las IPS, aumentan el riesgo en el manejo de la actividad (renuencia a atender a los afiliados al régimen subsidiado) y entraban las relaciones con las prestadoras. La lentitud en el giro de recursos desestimula a las promotoras y prestadoras, desfigura la esencia del sistema (aseguramiento de la salud) y explica el retiro de entidades promotoras o instituciones prestadoras del régimen subsidiado.

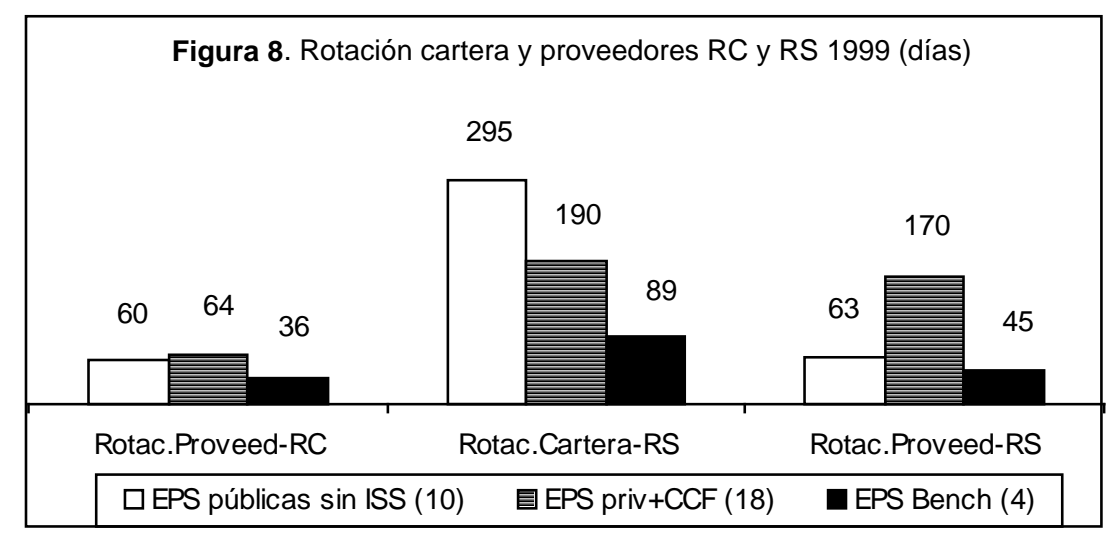

La rotación de proveedores (periodo de pago) expresa el número de días que se toma la EPS para cancelar sus compromisos con las IPS. Como lo muestra la Figura 8, las EPS demoran más de lo convenido el pago de los servicios de salud prestados por las IPS a sus afiliados en ambos regímenes. En 1999 el grupo de las EPS públicas demoró, en promedio, 60 días para cancelar la facturación auditada y aceptada de las IPS que dieron atención en salud a sus afiliados del régimen contributivo y 63 días en el subsidiado. El periodo de pago del grupo de EPS privadas y CCF, incluido Unimec, fue de 64 días para el RC y de 170 para el RS. Sin Unimec, el periodo de pago disminuye a 45 (RC) y 92 días (RS). Las EPS tomadas como parámetro de comparación presentan periodos de pago de 36 días para el régimen contributivo y de 45 días para las IPS que prestan servicios a sus afiliados del régimen subsidiado. El flujo de fondos de las EPS hacia las IPS es más demorado en el RC que su recuperación de cartera. En cambio, en el RS el pago de las EPS a las IPS es más ágil que el giro de los entes territoriales hacia las EPS.

La falta de fluidez de los recursos, en especial en el régimen subsidiado, obliga a las EPS, al igual que a las IPS, a adquirir créditos en el sistema financiero y a asumir costos por concepto de intereses, en detrimento de sus resultados (utilidades). Parte del problema se debe a la baja capacidad de gestión de las IPS en su proceso de facturación y cobro y parte a la práctica de los entes territoriales de demorar el giro para lograr rendimientos financieros que contribuyan a disminuir su problema fiscal. Esto hace pensar que las IPS deben establecer mejores estrategias de cobro y obliga a los entes de dirección y control del SGSSS a diseñar mecanismos efectivos que agilicen el flujo de recursos de los entes territoriales hacia las EPS y de éstas a las IPS.

IMPACTO DEL RÉGIMEN SUBSIDIADO EN LAS IPS 
En este aparte se analiza la información que entregaron 65 IPS públicas sobre ejecución presupuestal de ingresos, monto facturado y recaudado por concepto de atención a vinculados, y composición de cartera por edades. En vista del número de IPS que entregaron datos, los resultados y conclusiones no se deben generalizar.

Un total de 65 IPS públicas suministraron datos sobre ejecución presupuestal de ingresos. Debido a la dispersión de éstos, se toma información de 59 IPS cuyos datos permiten un análisis comparativo para el periodo 1997-1999. Estas IPS pertenecen al distrito capital y a 45 municipios de 25 departamentos. El mayor número de IPS públicas tomadas en el análisis pertenecen a Antioquia con 9, Valle con 8, Distrito Capital con 5 y Tolima con 4. Por niveles de atención 22 correspondieron al nivel 1, 25 al nivel 2, 12 al nivel 3 .

La Tabla 7 muestra el monto promedio anual de ingresos logrado por las IPS incluidas en el análisis, a precios corrientes de cada año y la Tabla 8, este monto a precios constantes de 2000, en millones de pesos deflactados por Índice de Precios al Consumidor. Este monto incluye ingresos por régimen subsidiado y contributivo, Soat-Ecat, otros servicios, vinculados, subsidios de oferta, ingresos financieros y otros ingresos.

Tabla 7. Ingreso promedio anual por IPS-ESE a precios corrientes

\begin{tabular}{ccrrrrr}
\hline \multirow{2}{*}{ Nivel } & \multirow{2}{*}{ Número de IPS } & \multicolumn{3}{c}{ Millones de pesos } & \multicolumn{2}{c}{ Variación } \\
\cline { 3 - 7 } & & 1997 & 1998 & 1999 & 1998 & 1999 \\
\hline 1 & 22 & 2501 & 3397 & 3726 & 35,8 & 9,7 \\
2 & 25 & 5739 & 7044 & 8612 & 22,7 & 22,3 \\
3 & 12 & 17217 & 21227 & 23113 & 23,3 & 8,9 \\
\hline Total & 59 & 6866 & 8569 & 9740 & 24,8 & 13,7 \\
\hline
\end{tabular}

Fuente: Datos suministrados por 59 IPS públicas. Inflación 1997=17,68 \%,

$1998=16,7 \%, 1999=9,23 \%$ (Banco de la República)

A pesos corrientes de cada año, las IPS públicas incluidas en el análisis muestran un fuerte incremento en el total de ingresos. La diferencia en el promedio de ingresos se explica por la diferencia en el grado de complejidad y costo de la atención ofrecida por cada tipo de IPS y por la diversidad de recursos físicos, científicos, asistenciales y administrativos disponibles en cada nivel.

A precios constantes de 2000 (Tabla 8), el ingreso promedio de las IPS de nivel 1 muestra un crecimiento real de 16,4 \% en 1998 y de apenas 0,4 \% en 1999. Las IPS de nivel 2 crecen más en 1999 (11,9 \%) que en 1998 (5,2 \%). Las IPS de nivel 3 muestran la evolución menos favorable en el ingreso promedio, que creció 5,6 \% en 1998 y decreció 0,3 \% en 1999.

Tabla 8. Ingreso promedio anual por IPS-ESE a precios constantes de 2000

Nivel Millones de pesos de 2000 Variación




\begin{tabular}{lrrrrr}
\cline { 2 - 6 } & \multicolumn{1}{c}{1997} & \multicolumn{1}{c}{1998} & \multicolumn{1}{c}{1999} & \multicolumn{1}{c}{1998} & \multicolumn{1}{c}{1999} \\
\hline $1(22$ IPS) & 3467 & 4035 & 4052 & 16,4 & 0,4 \\
2 (25 IPS) & 7956 & 8368 & 9366 & 5,2 & 11,9 \\
$3(12$ IPS) & 23868 & 25216 & 25136 & 5,6 & $-0,3$ \\
\hline Total (59 IPS) & 9518 & 10179 & 10592 & 6,9 & 4,1 \\
\hline
\end{tabular}

Fuente: datos suministrados por 59 IPS públicas. Inflación 1997=

$17,6 \%, 1998=16,7 \%, 1999=9,23 \%, 2000=8,75 \%$. IPC $1997=85,69 \%$,

$1998=100 \%, 1999=109,23 \%, 2000=118,79 \%$ (Banco de la República)

Como se puede observar en la Tabla 9, para el periodo de análisis (1997-1999), las principales fuentes de ingresos son la atención a vinculados y el subsidio a la oferta, que aportaron, para las 59 IPS públicas analizadas, el 53 \% del total de ingresos en 1997, el 48,3 \% en 1998 y el 45,6 \% en 1999.

Tabla 9. Composición del ingreso total de una IPS pública

\begin{tabular}{lrrr}
\hline \multicolumn{1}{c}{ Concepto de ingreso } & 1997 & 1998 & 1999 \\
\hline Régimen subsidiado & 13,3 & 16,6 & 17,5 \\
Régimen contributivo & 12,3 & 12,8 & 12,4 \\
Soat- Ecat & 4,0 & 4,3 & 4,6 \\
Otros servicios & 6,3 & 8,2 & 8,5 \\
Total facturado & 35,9 & 41,9 & 43,0 \\
Vinculados & 18,5 & 17,5 & 18,5 \\
Subsidio de oferta & 34,5 & 30,8 & 27,1 \\
Total subsidios de oferta & 53,0 & 48,2 & 45,7 \\
Financieros & 0,4 & 0,9 & 0,9 \\
Otros ingresos & 10,7 & 8,9 & 10,5 \\
Promedio (\$millones de 2000)=100\% & 9518 & 10179 & 10592 \\
\hline
\end{tabular}

Fuente: datos de ejecución presupuestal suministrados por 59 IPS públicas (22 de nivel 1, 25 de nivel 2 y 12 de nivel 3 ).

Es de destacar que la participación de los subsidios de oferta muestra una tendencia decreciente, pues pasa del 34,5 \% en 1997 al 27,1 \% en 1999. Esta fuente de ingresos participará cada vez menos en el total de ingresos debido a la política de cambio de subsidios de oferta a subsidios a la demanda y a la filosofía de afiliación universal a uno de los dos regímenes establecidos en la Ley 100/93 (contributivo o subsidiado).

Las IPS públicas de nivel 1 presentan una evolución contraria a la política de cambio de subsidios de oferta a demanda, pues la participación de los ingresos por atención a vinculados representa el $30 \%$ del total de ingresos y los subsidios de oferta el $19 \%$ en el periodo de análisis (1997-1999). El total de susidios a la oferta (vinculados y subsidios de oferta) representan, para las 22 IPS públicas de nivel 1 que entregaron información, el 48.7\% del ingreso total en 1997 y el 49.3\% en 1999, como se muestra en la Tabla 10.

Tabla 10. IPS públicas de nivel 1: composición del ingreso total

$\begin{array}{llll}\text { Concepto de ingreso } & 1997 & 1998 & 1999\end{array}$




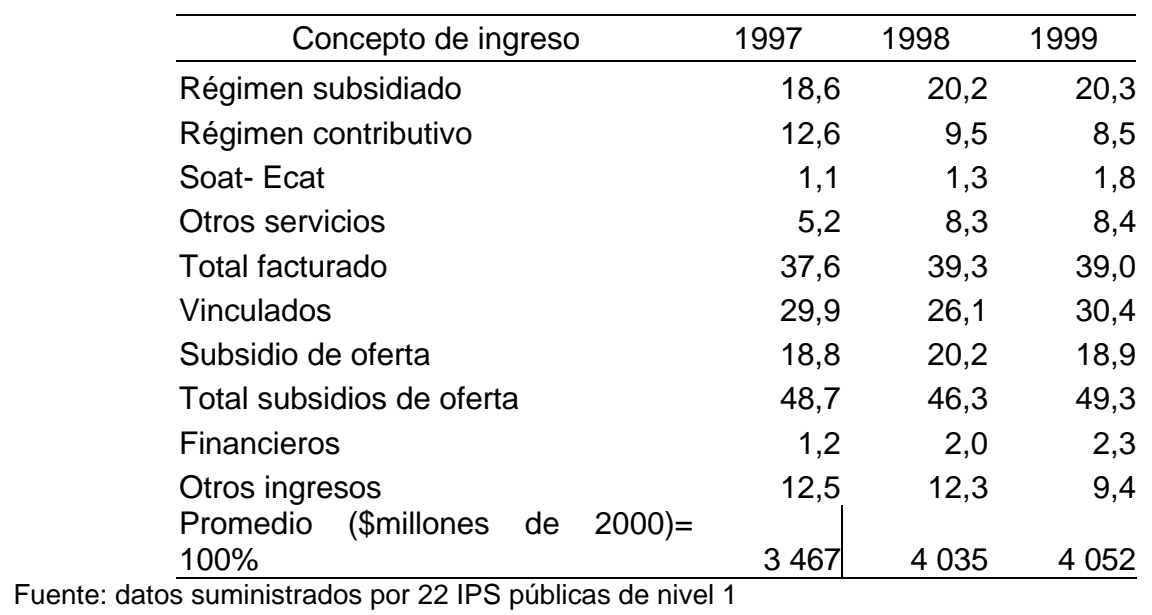

Las IPS públicas de nivel 2 y 3 analizadas muestran una tendencia más ajustada a esta filosofía, pues presentan decrecimiento en la participación de los vinculados o del subsidio de oferta en el total de ingresos, como se observa en la Tabla 11. Sin embargo, las IPS públicas mantienen una fuerte dependencia de estos dos tipos de recursos.

Una preocupación permanente sobre las IPS es su baja capacidad para facturar servicios y cobrar. Hacia 1999 las IPS obtenían el 43 \% de los ingresos de facturación de servicios, un 45,6 \% de subsidio a la oferta y un $11,4 \%$ de origen financiero y otros.

El esfuerzo que realizan las IPS públicas para mejorar su eficiencia, vía aumento de la facturación por servicios se ve contrarrestada por la mora de las entidades de aseguramiento (EPS, ARS, CCF, convenios) para cancelar el producto de dichos servicios.

Tabla 11. IPS públicas de nivel 2 y 3 . Composición del ingreso

\begin{tabular}{lrrr}
\hline \multicolumn{1}{c}{ Concepto de ingreso } & 1997 & 1998 & \multicolumn{1}{c}{1999} \\
\hline \multicolumn{1}{c}{ Promedio IPS nivel 2 (25) } & 10,0 & 13,2 & 15,2 \\
\hline Régimen subsidiado & 11,0 & 14,4 & 12,8
\end{tabular}




\begin{tabular}{lrrr}
\hline \multicolumn{1}{c}{ Concepto de ingreso } & & & \\
\hline Soat- Ecat & 1,8 & 2,0 & 2,7 \\
Otros servicios & 5,9 & 6,9 & 7,0 \\
Total facturado & 28,7 & 36,5 & 37,7 \\
Vinculados & 16,4 & 15,9 & 19,9 \\
Subsidio de oferta & 42,7 & 35,2 & 29,6 \\
Total subsidios de oferta & 59,0 & 51,2 & 49,5 \\
Financieros & 0,4 & 0,2 & 0,4 \\
Otros ingresos & 11,9 & 12,1 & 12,4 \\
Promedio (\$millones de 2000)=100\% & 7956 & 8368 & 9366 \\
\hline \multicolumn{1}{c}{ Promedio IPS nivel 3 (12 IPS) } & & & \\
\hline Régimen subsidiado & 14,2 & 18,0 & 18,4 \\
Régimen contributivo & 13,0 & 12,7 & 13,3 \\
Soat- Ecat & 6,4 & 6,8 & 6,9 \\
Otros servicios & 6,8 & 9,0 & 9,6 \\
Total facturado & 40,4 & 46,4 & 48,3 \\
Vinculados & 16,9 & 16,0 & 13,9 \\
Subsidio de oferta & 33,1 & 30,7 & 27,7 \\
Total subsidios de oferta & 50,0 & 46,8 & 41,6 \\
Financieros & 0,2 & 1,1 & 0,8 \\
Otros ingresos & 9,3 & 5,7 & 9,3 \\
Promedio (\$millones de 2000)=100\% & 2368 & 25216 & 25136 \\
\hline suministrados por 25 IPS públicas de nivel 2 y 12 de nivel 3 & & &
\end{tabular}

\section{ANÁLISIS DE ANTIGÜEDAD DE CARTERA}

El flujo de recursos entre los distintos actores que intervienen en el régimen subsidiado de salud (entes territoriales- ARS- IPS) es uno de los problemas que más inciden en los resultados y en la sosteniblidad del SGSSS. Los prestadores (IPS) afirman que las administradoras del régimen subsidiado (ESS, CCF, EPS) demoran demasiado el pago por los servicios de salud prestados y que esto genera dificultades financieras que limitan la posibilidad de actualización tecnológica, de ampliación de instalaciones, de mejoramiento de servicios, aumentan el riesgo en el manejo de la actividad, entraban las relaciones con su personal y sus proveedores, pueden restarle viabilidad a su operación y pueden producir desestímulo para atender a los afiliados al régimen subsidiado. La lentitud en el giro de recursos desestimula a las prestadoras, desfigura la esencia del sistema (aseguramiento de la salud) y explica el retiro de instituciones prestadoras del régimen subsidiado en detrimento del usuario, objeto final del sistema.

La falta de fluidez de los recursos, en especial en el régimen subsidiado, obliga a las IPS a adquirir créditos en el sistema financiero y a asumir costos por concepto de intereses, en detrimento de sus resultados (utilidades). 
Parte del problema se debe a la baja capacidad de gestión de las IPS en su proceso de facturación y cobro, parte a la práctica de los entes territoriales de demorar el giro a las ARS para lograr rendimientos financieros que contribuyan a disminuir su problema fiscal y parte a la práctica de las ARS (EPS, CCF, ESS) de demorar el proceso de revisión, aprobación y pago de la facturación de las IPS para lograr rendimientos financieros y mejorar su rentabilidad. Por esto, las IPS deben establecer mejores estrategias de facturación y cobro y los entes de dirección y control del SGSSS deben diseñar mecanismos efectivos que agilicen el flujo de recursos del régimen subsidiado de los entes territoriales hacia las ARS y de éstas a las IPS.

Para dimensionar el problema, a continuación se presenta el comportamiento de la rotación de cartera (periodo de cobro) por nivel de IPS y por tipo de ARS. La rotación de cartera (periodo de cobro) indica el número de días que se toman las ARS para cancelar sus compromisos con las IPS por concepto de servicios prestados a los afiliados al régimen subsidiado.

Para este análisis se toma la información suministrada por 60 IPS públicas sobre la antigüedad de su cartera a 2000. Aún cuando los datos tienen mes de corte diferente (junio a noviembre), esto no invalida las observaciones hechas al respecto. Las 60 IPS públicas reportan que 171 aseguradoras (109 ESS, 23 CCF, 18 DRS, 16 EPS y 5 convenios) $)^{2}$ les adeudan por concepto de facturación de servicios de salud un total de \$ 50697 millones, de los cuales \$ 29784 millones, es decir el 58,7 tenía más de 90 días de vencida (este rango incluye deudas de periodos anteriores con una proporción significativa de cartera irrecuperable). La Tabla 12 muestra, por nivel, la composición de la cartera promedio de una IPS pública.

Tabla 12. IPS públicas: análisis de antigüedad de cartera por nivel

\begin{tabular}{lrrrr}
\hline \multicolumn{1}{c}{ Días de vencimiento } & Nivel 1 & Nivel 2 & Nivel 3 & Prom.gral \\
\hline Menos de 30 días & 14,9 & 21,9 & 10,2 & 16,2 \\
De 30 a 60 días & 21,2 & 13,3 & 10,5 & 14,1 \\
De 60 a 90 días & 11,9 & 12,8 & 8,2 & 11,0 \\
Más de 90 días & 51,9 & 52,0 & 71,2 & 58,7 \\
Promedio por IPS (\$millones)= 100\% & 446,3 & 814,6 & 2231,6 & 845 \\
Antigüedad promedio de cartera (días) & 114 & 112 & 140 & 123 \\
Número de IPS & 26 & 26 & 8 & 60 \\
\hline de cartera suministrados por 60 IPS públicas & & & &
\end{tabular}

Fuente: datos de cartera suministrados por 60 IPS públicas

El mayor porcentaje de cartera corresponde al rango de más de 90 días, que incluye facturación de periodos anteriores, el cual asciende a 51,9 \% para las ESE del nivel 1, a 52 \% para el nivel 2, 71,2 \% para el nivel 3 y 58,7 \% a nivel promedio de las 60 IPS públicas que entregaron datos sobre antigüedad de cartera.

Con estos porcentajes se puede estimar la antigüedad promedio de la cartera mediante la suma de los porcentajes de cartera de cada rango de vencimiento multiplicado por los días promedio de cada rango. En este estudio se toman 15 días como promedio del primer rango (menos de 30 días), 45 para el segundo (de 30 a 60 días), 75 para el tercero (de 60 a 90 días) y 180 para el último (más

\footnotetext{
${ }^{2}$ Nota del Editor: ESS = Empresa Solidaria de Salud. CCF = Caja de Compensación Familiar. DRS = Dirección Regional (departamental o municipal) de Salud. EPS = Entidad Promotora de Salud. ARS = Administradora de Régimen Subsidiado. IPS = Institución Prestadora de Servicios de Salud.
} 
de 90 días). Este promedio de 180 días puede considerarse bajo, dado que en ese rango hay cartera vencida, posiblemente irrecuperable, de periodos anteriores.

En contra de lo esperado, las IPS de nivel 3, a pesar de contar con mayor capacidad de gestión, de negociación y de poder de presión sobre las aseguradoras (EPS, ESE, CCF, convenios) presentan la mayor antigüedad de cartera (mayor demora en recuperar su facturación). Los elevados promedios de antigüedad de cartera tienen incidencias negativas sobre la estructura financiera de las IPS y representan costos de oportunidad que deterioran la capacidad de inversión y la posibilidad de hacer rentable su operación.

Los datos de antigüedad de cartera de las 60 IPS públicas que entregaron datos al respecto permite estimar el tiempo que demoran las aseguradoras para pagar lo facturado por las IPS (Tabla 13).

Las 171 aseguradoras que recibieron servicios de las 60 IPS públicas analizadas deben a éstas un total de \$ 50697 millones, para un promedio por aseguradora de \$ 297 millones. Este promedio es de \$ 192 millones en el caso de las empresas solidarias de salud- ESS, de \$ 409 millones por parte de las cajas de compensación familiar- CCF, de \$1 002 millones de las entidades promotoras- EPS, \$ 92 millones de las direcciones regionales de salud- DRS (departamentales y municipales) y de \$ 98 millones de los convenios.

Tabla 13. Antigüedad de cartera de las IPS públicas por tipo de ARS (\%)

\begin{tabular}{crrrrrr}
\hline Días de vencimiento & ESS & CCF & EPS & DRS & CONV & Tot.gral \\
\hline Menos de 30 días & 13,7 & 20,7 & 14,3 & 24,5 & 50,6 & 16,2
\end{tabular}




\begin{tabular}{lrrrrrr} 
De 30 a 60 días & 13,6 & 14,3 & 15,4 & 2,5 & 9,7 & 14,1 \\
De 60 a 90 días & 10,2 & 12,9 & 11,8 & 0,5 & 55 & 11,0 \\
Más de 90 días & 62,5 & 52,1 & 58,4 & 72,4 & 34,4 & 58,8 \\
Total $(\$ M M)=100 \%$ & 192,1 & 408,9 & 1002,3 & 92,1 & 98,3 & 296,5 \\
Periodo medio de pago & 128 & 113 & 123 & 136 & 78 & 123 \\
Número de ARS & 109 & 23 & 16 & 18 & 5 & 171 \\
\hline
\end{tabular}

Fuente: datos de cartera suministrados por 60 IPS públicas ESS= Empresa Solidaria de Salud. CCF= Caja de Compensación Familiar. EPS= Entidad Promotora de Salud. DRS= Dirección Regional (departamental o municipal) de Salud. Conv= Convenio (entre CCF). ARS= Administradora de Régimen Subsidiado.

La antigüedad de la cartera en promedio de días, fue la siguiente:

ESS: 128

CCF: 113

EPS: 123

DRS: 136

Convenios: 78

El promedio total fue de 123 días.

Con metodología similar, se determinó la antigüedad de las cuentas registradas por las IPS públicas pendientes de pago por parte de las aseguradoras.

Los datos suministrados por las 60 IPS públicas muestran que la mayor demora en el cobro se presenta cuando una IPS factura al servicio de salud regional (departamental o municipal), con 136 días. Esta situación puede considerarse anormal, por cuanto la facturación debe hacerse con cargo a una aseguradora y no directamente al servicio regional de salud e indica que las IPS públicas que muestran esos valores desconocían la normatividad, lo que les puede significar la pérdida de lo facturado. La antigüedad promedio de las cuentas por cobrar a las otras aseguradoras es de 128 días (ESS), 123 días (EPS), 113 días (CCF) y 78 días (convenios). Esto refleja una débil gestión de cobro por parte de las ESE y una cultura de no pago por parte de las aseguradoras.

Es necesario que las IPS mejoren sus procesos de facturación y su gestión de cobro y que los entes que regulan y controlan el SGSSS diseñen mecanismos efectivos para garantizar el pago oportuno de las aseguradoras a las IPS, a fin de evitar que las prestadoras de servicios, que son las que finalmente garantizan los servicios a los afiliados, se vean forzadas a suspender sus operaciones por incapacidad de cubrir los compromisos con el personal o con sus proveedores, o vean deteriorada su posibilidad de respuesta por atraso tecnológico derivado de su poca capacidad de inversión. El problema es doble: no pago de las IPS, demostrado por los altos promedios de antigüedad de cartera de las IPS públicas incluidas en este análisis, y demora en el pago por parte de las aseguradoras

\section{REFERENCIAS}

1. Ministerio de Salud, Universidad Nacional de Colombia. ¿Ha mejorado el acceso en salud?. Evaluación de los procesos del régimen subsidiado. Bogotá: Unibiblos. 2002. ISBN 958-701-251-8. 
2. Ministerio de Salud, Universidad Nacional de Colombia. Los avatares del servicio de salud para pobres. Transformación de subsidios de Oferta-Demanda sostenibilidad financiera comparación internacional. Bogotá: Unibiblos. 2002. ISBN 958-701-265-8.

3. Ministerio de Salud, Universidad Nacional de Colombia. Hacia una reforma del Sistema de Seguridad Social: salud, pensiones y riesgos profesionales. Bogotá: Unibiblos. 2002. ISBN 958-701-254-2.

4. Sánchez F, Núñez J. Descentralización, pobreza y acceso a los servicios sociales. ¿¿Quién se benefició del gasto público social? Coyuntura Social. 1999; 20.

5. Gómez BH (compilador) ¿Para dónde va Colombia?. Tercer Mundo, Colciencias, Bogotá; 1999. 